\section{IJIKMMENA}

2,2

131

\title{
CLEAN ENERGY AWARENESS CAMPAIGNS IN THE UAE: AN AWARENESS PROMOTERS PERSPECTIVE
}

\author{
Noor Ghazal Aswad' \\ International Renewable Energy Agency (IRENA), Abu Dhabi
}

\section{Yasser Al-Saleh ${ }^{2}$}

INSEAD Innovation \& Policy Initiative, Abu Dhabi, and

\section{HananTaleb ${ }^{3}$}

British University in Dubai, Dubai

\begin{abstract}
Purpose: This paper presents an overview of recent public awareness campaigns on CE issues in the Gulf Cooperation Council (GCC) region. It also provides an in-depth case study of the United Arab Emirates (UAE), examining the obstacles and successes such campaigns have encountered in the country. As part of this work, the objectives of these CE awareness campaigns, the groups they have targeted, the institutions behind them, the level of support they have garnered and their impact are assessed.

Design/methodology/approach: Besides a critical review of various secondary sources (publicly available and otherwise), the paper reports on the findings of in-depth interviews conducted with several professionals engaged in CE awareness-raising activities in the UAE.
\end{abstract}

International Journal of Innovation and Knowledge Management in Middle East \& North Africa Vol. 2 No. 2, 2013

Copyright $@ 2013$ WASD
${ }^{1}$ Noor Ghazal Aswad, International Renewable Energy Agency (IRENA), Abu Dhabi, UNITED ARAB EMIRATES, Email: nghazalaswad@irena.org

${ }^{2}$ Yasser Al-Saleh, INSEAD Innovation \& Policy Initiative, Abu Dhabi, UNITED ARAB EMIRATES, Email: Yasser.alsaleh@INSEAD.edu

${ }^{3}$ HananTaleb, British University in Dubai, Dubai, UNITED ARAB EMIRATES, Email: hanan.taleb@buid.ac.ae 
Findings: It has become apparent that most of the $\mathrm{CE}$ awareness initiatives conducted in the UAE have focused on the demand side-energy management, whilst overlooking the need to create an enhanced awareness of energy sources used. Moreover, the paper identifies a number of potential success factors for CE awareness initiatives, such as embedding carefully targeted messages that appeal to the audience of the campaigns.

Originality/value: The paper provides policy recommendations on the most suitable ways to engender awareness of the benefits of CE as a means to

Clean energy awareness campaigns in the UAE achieve sustainable development goals and how to most effectively stimulate public participation in the UAE, and across the GCC region.

Keywords: Gulf Cooperation Council, United Arab Emirates, Clean energy, Public awareness campaigns

Paper type: Research paper

\section{INTRODUCTION}

Generally speaking, public awareness campaigns play an important role in raising the awareness of the public and in drawing their attention to the risks and/or advantages of certain behaviour. If effective, they can even encourage their target groups to review and possibly alter their values, habits and even lifestyles. For instance, the promotion of public safety and public health relies to a large extent on public benefit campaigns, such as those that call for safer driving habits, for the avoidance of alcohol or drugs and for the wearing of seat belts in private cars or public transportation. Such campaigns draw the attention of consumers to the dangers of accidents or to the "internal" (personal) and "external"(public) costs of certain activities or consumption.In this regard, public benefit campaigning has played a crucial role in the propagation of certain patterns of consumer behaviour in many countries (Kyung-Hee, 2007). For instance, when seat belts were first introduced in the United States, the public were often unaware of the advantages of these devices and were reluctant to accept their installation. However, greatly as a result of strong public awareness campaignsalongside law enforcement, seat belts have found increasing acceptance in society (Dinh-Zarret al., 2001).

This paper aims to provide an examination of recent awareness campaigns on clean energy (CE) solutions in the Gulf Cooperation Council (GCC) region, with a special focus on the United Arab Emirates (UAE). The paper is structured as follows. Firstly, a discussion 
IJIKMMENA

2,2

is provided on the role of public campaigns to support the CE agenda worldwide. This is followed by a brief overview of the status of $\mathrm{CE}$ in the GCC region, as well as that of CE campaigns across the GCC region. An account of the research methodology used to conduct the research is then provided, after which the research findings are presented. These include an overview of the caseof the UAE as far as CE awareness campaigns are concerned, as well as a detailed analysis of the obstacles, successes and perceptions surrounding these campaigns. The paper concludes with a summary of the key findings and policy recommendations on the most suitable ways to engender awareness of the benefits and applicability of $\mathrm{CE}$ as a means to achieve sustainable development goals and how to most effectively encourage public participation in the CE sector in the UAE.

\section{THE ROLE OF PUBLIC SUPPORT IN CLEAN ENERGY DEPLOYMENT: A GLOBAL PERSPECTIVE}

It is often argued that public awareness campaigns are vital for policy makers and implementers as they constitute an important element in the support of CE innovation policies and programmes (Okaka, 2002). Public acceptance is, therefore, recognised as a critical factor shaping the widespread implementation of CE technologies and the achievement of environmentalpolicy targets (Ekins, 2004).Moreover, it is commonly assumed that public attitudes need to change to ensure that more radical scenarios about the implementation of CE technologies areplausible (Devine-Wright,2008). This also appears to applyin the context of the GCC, as a recent scenarios study has considered public perception to be one the most decisive prerequisites for renewable energy innovations to penetrate the power market of Saudi Arabia (Al-Saleh, 2009).

Another factor that highlights the political importance of public attitudes is that, in the recent past, there has been widespread opposition to various CE developments, such as wind and biomass, around many parts of the world (Toke, 2002; Upham and Shackley, 2006). One of the most documented reasons for public opposition concerns the visual impact of wind turbines on the landscape (e.g. see Graham et al., 2009; Warren et al., 2005; Zoellneret al., 2008). On some occasions, public opposition resultsfrom a lack of knowledge of improvements in CE technologies and their enormous potential. Some may overlook the fact that $\mathrm{CE}$ technologies have improved over the last few years; others may not understand the need for CE from the outset, 
or have only a limited understanding of the motivations behind CE investments. For example, although one of the primary drivers behind investment in renewable energy is climate mitigation, the public may not necessarily realise the association between $\mathrm{CE}$ and protection of the environment. This was evident in a recent study undertaken in Greece, which illustrated that whilst the majority of the public believe that climatic changes are related to the consumption of fossil fuels, a much smaller proportion think that this could be addressed with the use of renewable energy technologies and CE solutions (Savvanidouet al., 2010).Furthermore, there are reports of inaccurate risk perception amongst the public towards some renewable energy technologies as a result of being misinformed of CE developments.

To combat such phenomena, many studies (including Day and Monroe, 1999; Robitaille and Etcheverry, 2005) have suggested that such views can be alteredthrough innovative educational strategies aimed at increasing awareness, political support, local capacity development and know-how. According to Rogers (1995), the diffusion rate of technologies within societies can also be influenced through "observability", the extent to which the results of an innovation are visible to people. Examining the diffusion of CE technologies, Sawin (2004) further argues that education and information dissemination are necessary, not only to inform potential investors and customers about the much-needed potential of CE, but also to develop a trained workforce that is able to produce, install and maintain CE equipment. Jackson (2005), who conducted an extensive review of the literature related to "consumer behaviour" and "behavioural change", suggested a broad model for encouraging "sustainable innovation". In essence, he argued the need for strategies that enable (e.g. through removing barriers), encourage (through providing incentives) and engage people in the move towards "sustainable development", whilst governments simultaneously lead by example.

Informing the public about the need for CE technologies is clearly important, as even when governments provide the necessary infrastructure; their efforts are likely to ultimately fail without the collaboration of the public. A review of the experiences of countries currently prominent in the $\mathrm{CE}$ arena illustrates that a strong level of public support has always been essential to the success of their renewable energy industries. For instance, several studies have affirmed that Germany only started to pave its way towards become a leading renewable energy force
Clean energy awareness campaigns in the UAE 
IJIKMMENA

2,2

after a series of effective policy interventions came into place as a result of a strong anti-nuclear and environmental movement driven by public concern (Jacobsson and Lauber, 2005; Lauber andMez, 2004). This is particularly the case in democratic societies, where the public can exercise considerable influence on both the rate of technological diffusion and on the political agenda (e.g. see Bauer,1997; Dolata, 2005; Frey, 1993).

It is interesting to note that, in contrast to the 1970s and 1980s, today's public unease concerning new energy technologies has been actively addressed not only by non-governmental organisations (NGOs) and environmental associations, but also by a wide variety ofother stakeholders, such as citizens, voters and consumers, who have been very involved in promoting the CE cause. In order to assess the impact of such activities, several opinion polls have been launched in recent years to gather and quantify the public's attitude towards CE technologies. These surveys, mostly published on the internet and in various periodicals, vary in their results-according to the scope of the survey-in terms of sample population and types of energy technology. Examples of countries that have performed national-level surveys include the United Kingdom (British Wind Energy Association, 2005), the United States of America (Boise State University, 2008) and India (Chandrasekar and Kandpal, 2007). In addition, there exist many surveys that cover a large sample population across Europe (e.g. Eurobarometer, 2006) or around the globe (e.g. World Public Opinion, 2006). In addition to such surveys, there is also substantial case-based, qualitative, theoretical and empirical literature on the psychology and sociology of behaviour and attitudes in relation to renewable energy (e.g. Devine-Wright, 2005; Owens and Driffil, 2006; Upreti, 2004). Evidently, these studies all indicate that varying perceptions with regards to the acceptability of different renewable energy technologies are likely to exist in different parts of the world. Nevertheless, one main conclusion arising from such studies is that public support isan important factor to be considered for the successful deployment and diffusion of CE technologies within societies.

\section{A CLOSER LOOK AT THE GCC REGION}

This literature review section provides a brief account of the status of CE within the GCC countries, with a particular focus on the UAE. Thisis thenfollowed by a description of CE awareness initiatives that took place in the GCC region. 


\section{CLEAN ENERGY IN THE GCC REGION}

Oil and gas resources have driven economic growth in GCCcountries, including the UAE, throughthe generation of export revenues and allowing the development of infrastructure thatmeets the needs of the growing population. In the UAE, Abu Dhabi in particular has abundant hydrocarbon resources, holding 94 per cent of the UAE's proven oil reserves and 90per cent of its natural gas reserves (Luomi, 2009; Krane, 2010). The UAE has recently shown a keen interest in engaging in a more sustainable development path, including the deployment of RE technologies. Various initiatives have been launched and major RE projects are being developed, demonstrating the commitment of the UAE to tap into alternative sources and transform the country into a regional hub for sustainable energy. Abu Dhabi also recently set a target of deriving sevenper cent of its electricity from renewable sources (at the time of peak demand) by the year 2020 (Vidicanet al., 2012). A look at the literature indicates that there are several strong strategic and economic drivers behind the commitment to transition to a more sustainable economy,such as the abundant resources in this region, the finite nature of hydrocarbon resources and the rapid technological development ofCE technologies (Ferroukhiet al., 2012). In addition, heavily subsidised, rapidly growing domestic energy consumption in the UAE reduces hydrocarbons export volumes and revenues (AlSaleh, 2010). Another important driver is concerns about the UAE's increasingly damaging portrayal in the international policy arena, as a result of being one of the highest per capita emitters worldwide (Levitt, 2009; Reiche, 2010).

It should be recognised, however, that whilst renewable energy is important for achieving a sustainable energy future for the hydrocarbon-rich GCC region, it is not the only CE option available. Other CE meanswhich have recently gained interest in the region include enhancing energy efficiency, as well as prospects for capturing $\mathrm{CO} 2$ and storing it in deep rock formations for long term storage - a process commonly referred to as Carbon Capture and Storage (CCS). A recent study concerning the emerging CCS industry in Abu Dhabi pointed out that the role of public opinion is negligible in influencing critical decisions in this capital-intensive industry (Theeyattuparampilet al., 2012). However, it is interesting to note that a lack of sustainability awareness and lacklustreconcern towards energy and environment areoften reported as the main
Clean energy awareness campaigns in the UAE 
IJIKMMENA

2,2

barriers that hinder CE initiatives in the GCC region (Al-Saleh and Taleb, 2010; Al-Saleh and Vidican, 2012;Doukaset al., 2006; Taleb and Pitts, 2009). One example that alsoindicates the lack of public interest with regard to energy-related matters is a study(drawing on data from expert interviews) which revealed that the majority of Saudi citizens hold the view that oil will "last forever" and that "peak oil" and "global warming" are nothing but politicallydriven lies created by the west in order to create a market for CE technologies (Al-Saleh, 2010).

When considering the case of the GCC region, it is important to bear in mind that this region does not traditionally enjoy the same high levels of democracy and public participation as those experienced around many other parts of the world. A recent editorial on the topic of environmental awareness in the Arab world argues that "It is often not the case that strong public support for a certain cause will drive government policy in this region"(A1-Saleh, 2011). It purports that to date, public participation has been restricted to supporting government policies rather than influencing their direction or questioning their utility.

Moreover, while climate change-related mitigation policies are usually advocated from the bottom-up by an active civil society and an informed public, the CE policy-making process in the GCC countries has largely been based on a top-down approach. For the time being, civil society and environmental NGOs continue to have limited bearing on formulating national policy choices and technology diffusion strategies in the GCC region. However, the situation may change as a result of the wave of democracy, commonly referred to as the "Arab Spring", which has recently swept across the Middle East, although less so in the GCC region (mainly only in Bahrain and to a lesser degree Oman; Toumi, 2011). Hence, one would expect an increase in the role of NGOs, not only in terms of engagement with civil society, but also in the promotion of transparent policy-making and grassroots-initiated innovation (Al-Saleh, 2011). Thus far, the top-down approaches have worked somewhat to the advantage of the sustainability agenda in the GCC - partially because lobbying the monarchy would require fewer resources and less effort. Other factors that have somewhat neutralised the resistance to CE witnessed elsewhere in the world include the continuation of substantial subsidies for petroleum-based 
products and the fact that GCC governments have not imposed any environmental taxes. At the same time, the GCC region has made rather extensive use of awareness campaigns and to a lesser extent regulations to change public behaviour. Adopting such measures that have low political costs works well with the political economy setting of the GCC region, because imposing a heavy tax burden could place the authoritarian power of the GCC governments under public scrutiny (Reiche, 2010).

\section{CLEAN ENERGY AWARENESS CAMPAIGNS IN THE GCC REGION}

At a regional level, the GCC Supreme Council has highlighted the importance of "joint environmental action for....raising environmental awareness among citizens and conservation of natural resources" (The Cooperation Council for the Arab States of the Gulf, 2009). The Council has introduced mild guidelines to promote environmental awareness and education, such as an "Environment Week" held in the GCC states every February, which grants awards for the most outstanding environmental initiative carried out in the region. The Council has also supported the inclusion of environmental concepts in education curricula and in television programmes to increase general awareness of climate change (GCC Secretariat General, 2009). A closer look at the public awareness campaigns in the GCC reveals that most of these activities have focused on the environment and climate change, in particular greening projects, clean-up campaigns, workshops and seminars, conferences, training and public lectures (Raouf, 2008). As yet, there have been very few initiatives that have been developed primarily targeted at raising awareness of the benefits of renewable energy at the regional level. To that end, one initiative of note is the formation of the EU-GCC Clean Energy Network, established to increase knowledge and information between the EU and GCC region on sustainable, clean and renewable energy (EU-GCC, 2012). The global media coverage of Masdar City in Abu Dhabi has also been said to have contributed to a rising public awareness regarding $\mathrm{CE}$ around the world (Reiche, 2009). However, it appears there is still room to promote CE solutions at thelocal level.

NGOs have been one of the most effective entities driving CE awareness campaigns worldwide. However, environmental NGOs working in the GCC regionhave been said to face several barriers in carrying out their activities. The most important of these isa lack of
Clean energy awareness campaigns in the UAE 
IJIKMMENA

2,2

funds and volunteers, which results in a lack of effectiveness in lobbying for their causes (Raouf, 2008). To that end, Brohmannet al. (2007) argue that for public awareness initiatives to be successful, they must take into account both cultural factors (such as the trust of the public in institutions; a tradition of top-down versus bottom-up initiatives; environmental awareness; historical experience; and attitudes to new technology) and socio-economic and infrastructural factors (such as availability and perception of natural resources; interest in employment opportunities and regional economic development; perception of foreign investment; importance of energy independence; energy prices; technology and other input costs and competing technologies and industries). Another commonly reported shortcoming with regard to awareness campaigns (that is of relevance to $\mathrm{CE}$ awareness initiatives in the GCC region) is a lack of knowledge among the campaign practitioners, evaluators and their sponsors about the right methods for effective communication campaigns (Coffman, 2002).

Having established a basic understanding of the potential roles of CE awareness campaigns as well as their current status in the GCC region, it is of interest now to examine the case of the UAE in more detail. A primary research initiative was launched in the UAE with the intention of presenting new insights about previous CE awareness-raising initiatives. There is no doubt that public acceptance is becoming increasingly important for technology development and diffusion around the world (including the UAE, which is still at an early stage in the development of its CE sector). Therefore, a deeper understanding of the obstacles and successes that CE campaigns have encountered in the country is important to inform future undertakings. Currently, information concerning local experiences in this regard and an understanding of how public engagement with CE technologies is constructed and practised in the UAE is limited, with no studies having been conducted on the topic. With this in mind, the next section gives details of some of the methodological aspects of this researchproject.

\section{RESEARCH METHODOLOGY}

While carrying out this research, we were guided by the objective of exploring the experiences and concerns of those responsible for the development of CE awareness initiatives in the UAE. To obtain a more comprehensive understanding of the topic at hand and to supplement information gathered from secondary sources of information,primary 
data was gathered from semi-structured interviews. Between March and April of 2012,a total of eightsemi-structured interviews were conducted with professionals on a broad range of issues related to the topic of the research study. This was in order to explore their opinions and concerns about the challenges and opportunities surrounding CE awareness initiatives in the UAE. All interviews were conducted in person or over the phone, recorded and ranged in length from 20 to 90 minutes.

The criterion for selecting the interviewees was that each person should have been active in creating awareness around the CE field, so as to be well able to draw upon their personal experiences. Thus, the interviewees in the participant sample were carefully chosen based on research into well-known individuals whose accomplishments could be established via the internet, newspapers, published work, speeches and other pertinent material. In other words, a judgmental sampling technique was used. According to Saunders et al. (2007), such a sampling strategy is usually recommended for explorative and/or qualitative studies, especially when there are a limited number of people involved in the area being researched. The "snowball" technique was also used as a supplementary sampling technique.Interviewees themselves were asked to recommend other individuals who they believed would be knowledgeable on the study topic.

Ultimately, experts working in the UAE in different industries in the public and private sectors, as well as academia and NGOs were interviewed. Table 1 shows the list of interviewee affiliations.

\begin{tabular}{ll}
\hline Affiliation & Department \\
\hline Environment Agency - Abu Dhabi & $\begin{array}{l}\text { Environmental Information, Science } \\
\text { and Outreach } \\
\text { Environment Education Department }\end{array}$ \\
$\begin{array}{l}\text { Environment Agency - Abu Dhabi } \\
\text { Environment Agency - Abu Dhabi }\end{array}$ & Environment Education Department \\
Masdar Institute & Outreach Programmes \\
Emirates Environmental Group & Confidential \\
Major Newspaper (confidential) & Columnist \\
$\begin{array}{l}\text { Private University in the UAE } \\
\text { (confidential) }\end{array}$ & Engineering - Renewable Energy \\
$\begin{array}{l}\text { Private Company that Sells Solar Energy } \\
\text { Products (confidential) }\end{array}$ & Marketing \\
\hline
\end{tabular}

Clean energy awareness campaigns in the UAE 
IJIKMMENA

2,2

The semi-structured in-depth interviews were guided by an interview protocol, prepared beforehand and tailored specifically according to the experience and knowledge of the interviewees. The interviewees were given an overview of the research project and how the interview would be conducted, as well as being assured of the complete confidentiality of their views. At the start of the interview, an effort was made to emphasise that the interviewees' identities would not be divulged in the paper. This strategy helped to gain the confidence of the respondents, and increased the likelihood of them expressing their views more openly. They were also given the opportunity to ask for any clarifications or questions before the start of the interview. The interview protocol followed the archetypical "triangular" shape from the general to the specific (Hurworth, 1996; Walter and Gutscher, 2011), where broad questions were first asked on their educational background and work experiencein order to set the participant at ease. They were then asked about their current work responsibilities, after which questions were directly related to the topic at hand. Towards the end of the interview, key questions were asked (activities used to influence acceptance of CE, success factors of $\mathrm{CE}$ awareness programmes, the need for action, etc.). The full interview protocol is found in Appendix A.

The majority of interviewees did not object toaudio-recording of the actual interviews, allowing for transcripts to be prepared for qualitative analysis. The research findingswere analysed iteratively, moving back and forth between data collection, analysis and literature. This allowed for engagement with the data in a structured way, finding patterns and testing hypotheses in a consistent manner across the different interviewees. In order to enhance the procedural reliability of the research (Flick, 2006), memos were written directly after the completion of each interview. This was to help capture thoughts, opinions and perceptions of the transcript prior to coding. In addition, an effort was made to confirm data obtained from primary sources by checking againstdata obtained from secondary sources.

After incorporating the data with extensive notes taken during the data gathering stage, the multiple data sources were integrated to develop themes around issues surrounding public awareness campaigns on CE in the UAE. Additional information was also collected and reviewed in order to provide a contextual backdrop from which to understand more clearly the obstacles and successes CE awareness campaigns in the UAE have faced. 


\section{RESEARCH FINDINGS}

Using insights gained primarily from interviewing active CE awareness promoters, this section provides a detailed discussion of CE awareness campaigns that have recently taken place in the UAE, followed by an examination of the obstacles and successes such campaigns have encountered in the country.

\section{CLEAN ENERGY AWARENESS INITIATIVES IN THE UAE}

It has become apparent from our research that, when compared to other GCC countries, the UAE is doing well in terms of the level of CE awareness. Since 2007, an effort has been made by the Environment Agency of Abu Dhabi to regularly measure both CE awareness and behaviour by asking the general public questions about a range of environment-related issues, including their willingness to use energyefficient appliances. These enquiries have endeavoured to understand the role of influencing bodies such as the media, academics and commerce and their contribution to raising awareness and changing the behaviour of different sectors of the public. The primary objective behind this annual Environment Awareness and Behaviour Survey is to identify priority issues from an educational and behavioural perspective and to ascertain what people want from the government in order to help them to live more sustainably4.The most recent survey revealed an increase of both awareness and CE-conscious behaviour across the emirate from an initial level of 49per cent to 58.5per cent over the period 2007-2011. This significant improvement is largely attributable to the launching of extensive awareness raising activities in the UAE (Abdul Kader, 2011). Based on findings that emerged from both primary and secondary sources of information, Table 2 covers some of the most important CE awareness campaigns that have recently taken place across the UAE. This table includes awareness campaigns taking place through various media means by the UAE Ministry of Environment and Water; the Masdar Initiative; Abu Dhabi Water and Electricity Authority (ADWEA); and Dubai Water and Electricity Authority (DEWA).

As can be seen, the Masdar Imitative, geared towards the advancement, development and commercialisation of renewable and alternate energy technologies (as part of the country's aim to diversify

${ }^{4}$ Source of information is from an internal document provided by an interviewee at the Environment Agency-Abu Dhabi.
Clean energy awareness campaigns in the UAE 
IJIKMMENA

2,2

its energy portfolio) has been particularly active in the promotion and marketing of its renewable energy projects to the public in the UAE. It emerged from our interviews that the Masdar Institute (i.e. one of the five components of the Masdar Initiative) has been one of the main actors driving CE awareness in the UAE. The Masdar Institute has been quite active in promoting outreach activities to the younger public and larger community - extending to high school as well as university students. However, since 2011, the institute has pulled back from many of its activities in schools (which used to include delivering lectures, workshops and lab activities) and has recently focused on running the YFEL programme and recruiting Emirati university students through offering internships focusing on CE-related subjects.

\section{OBSTACLES AND SUCCESSES OF CLEAN ENERGY AWARENESS INITIATIVES IN THE UAE}

It became apparent in our discussions with interviewees that the government of the UAE (a monarchy made up mostly of the ruling elite of the royal family) acts as a strongly paternalistic and supreme decision maker, where decisions take place at the uppermost level of government authority and society remains deeply committed to traditional tribal roles. This characteristic differentiates the UAE's model of governance from many other developed and developing countries, meaning that the growth of a renewable energy industry - for instance-hinges strongly on political decision-making at the upper levels of government. Interviews indicated that particularly with regards to diversifying the energy mix and the UAE's energy strategy, the decision-making process has primarily been based on a "top-down" approach, where the government has initiated the majority of CE projects and the public have had a limited role in this regard. This closely mirrors findings from a recent study on the role of public opinionregarding decisions in the oil and gas industry, "due to the nature of the governing structure in Abu Dhabi,public opinion does not influence decision-making for oil and gas industry projects" (Theeyattuparampilet al., 2012, p. 11).It was also highlighted that the potential for community-led initiatives and interest groups to bring about grassroots change in the energy mix is limited.5 Although public opinion is usually expected to influence national priorities and the acceptability —as well as the acceptance — of new technologies, this does not appear to necessarily be the case in the UAE. As such, some interviewees stated that there is a perception among policy makers that

${ }^{5}$ This has also been reported by Vidicanet al. (2012). 


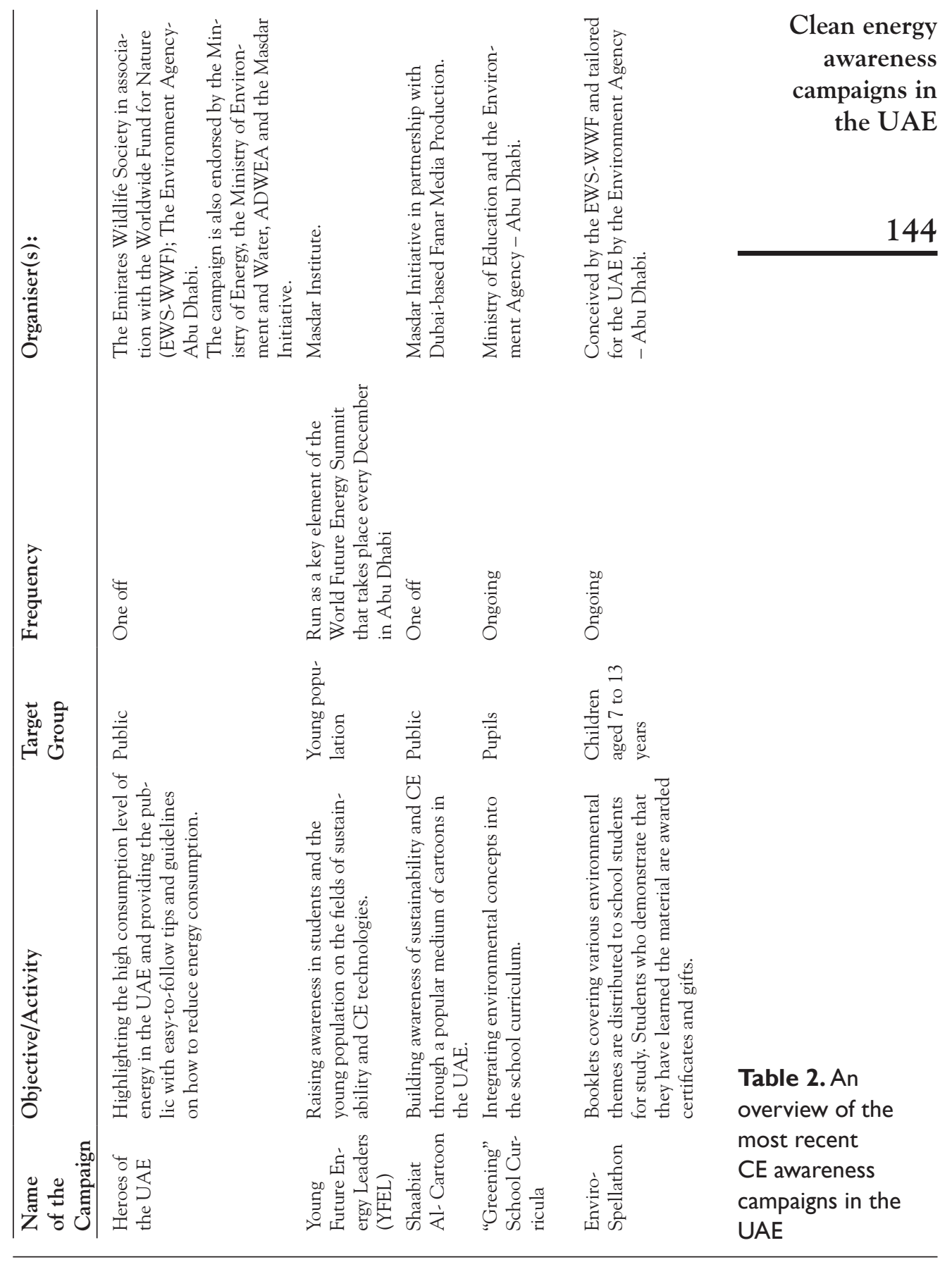




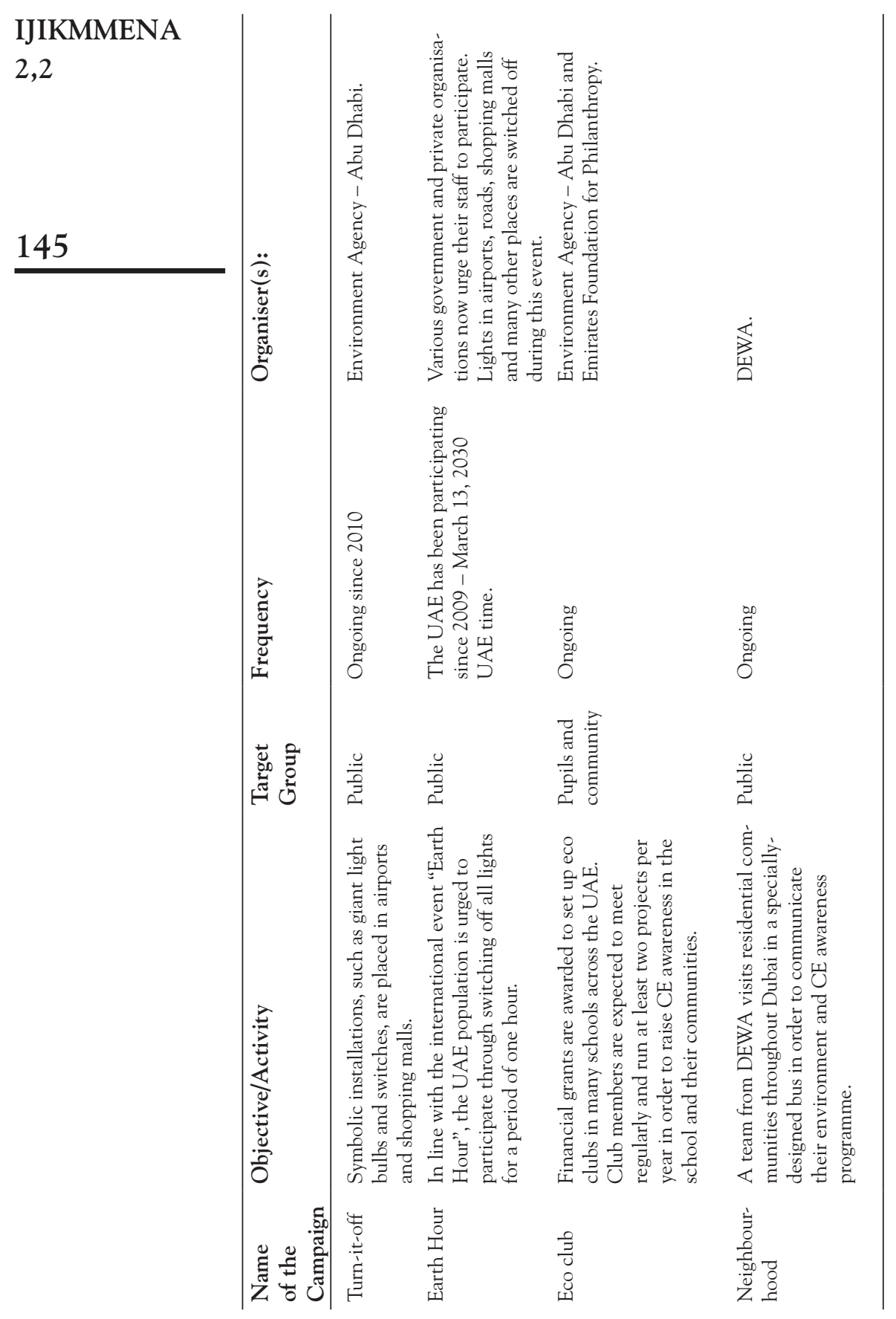


the transition of the UAE to a CE future does not necessarily require the public's support to succeed; i.e. there is no urgent need to create awareness among the public with regard to $\mathrm{CE}$ sources and their potential in the region at the current time.

Several factors appear to be making an inadvertent contribution to the public's lack of interest in CE sources. Rapidly growing domestic energy consumption derived from conventional energy sources is currently being heavily subsidised in the UAE (El-Husseiniet al., 2009). Domestic electricity tariffs range between USD 0.008 and USD 0.041/ $\mathrm{kWh}$ (depending upon the remoteness of the area and nationality), which equates to around only 20 to 60per cent of production costs (Mezheret al., 2011). These subsidies do not distinguish between the time of day or year and there is no adjustment based on customer consumption levels. 6 These subsidies, which are usually in the form of state-imposed tariffs and tax-free regulations (Qader, 2009), often result in electricity prices which do not accurately reflect to consumers the depleting nature of resources or the associated environmental costs. Therefore, although in the majority of countries the cost of using energy is borne by the consumer rather than through public finances, in the UAE consumers have little or no incentive to use energy efficiently and to avoid engaging in wasteful practices, asthe sourcing of their energy has no direct impact on the consumer.

Nevertheless, interviewees indicated that in the coming decade, public awareness and concerns about pollution and climate change could shift dramatically if energy prices continue to rise and subsidies are slowly removed. There have already been some steps forward in this regard. Recently, the GCC states have started reducing subsidies and the UAE increased gasoline prices in April and July of 2010, which although still below international prices, became the highest in the GCC (IEA, 2011). From March 2012, a new utility bill for water and electricity was put into place across the Emirate of Abu Dhabi,as an indicationof the government subsidy. Additionally, residential customers will have two consumption bands, showing the "ideal-average" and above "idealaverage" range of consumption (Anoop, 2012).

${ }^{6}$ Such tariffs are indeed very low when compared with other countries. For example, while electricity tariffs in the UAE range between $\$ 0.01$ and $\$ 0.04 / \mathrm{kWh}$, tariffs in the United States of America are around $\$ 0.11 / \mathrm{kWh}$ - also significantly lower than levels in most European countries (EIA, 2010).
Clean energy awareness campaigns in the UAE 
IJIKMMENA

2,2

However, it must be noted that interviewees were sceptical that such subsidy reductions would continue, indicating that continuing steps in this direction may be difficult to implement, mainly as a result of the strong political and social reasons which exist behind the current level of subsidies.7 Nevertheless, should subsidies indeed be significantly reduced, it could allow for a renewed government interest towards initiating public awareness campaigns specifically targeted on raising awareness about renewable energy sources.

Another of the main findings arising from our discussions was that initiatives to raise awareness on CE appear to have mostly been focused on demand side-energy management (i.e. end use consumption, particularly energy efficiency) as opposed to creating an enhanced awareness of energy sources used. So far, initiatives have focused on encouraging people to become more efficient in the manner in which they use energy, but have not addressed to the same degree the issue of which energy sources (in particular renewables) are used. As one interviewer stated, the focus of awareness initiatives has been more on "how people do things and use what we use more efficiently, as opposed to where they get energy from". The interviewee stated that "Certainly, there is a need for people to understand resources... in terms of where they get their energy from. There is really not much say that the public has on that issue, perhaps elsewhere, but not here". Another factor contributing to this is that the supply of energy in the UAE is a government monopoly where no competitive market truly exists: "how energy is produced is a government decision and the public does not really have much choice. The public's decision is only to use the energy efficiently".

Last, but certainly not least, one of the most important elements behind the success of CE awareness campaigns is the underlying messaging behind the campaign. In order for an awareness programme to effectively alter the attitudes of energy users and resonate with the public, messages need to be carefully developed and targeted (Manjunath, 2007). To that end, it has emerged that one of the most effective means to attract the attention of the local people are those relating environmental protection with Sheikh Zayed's and Islamic teachings. It is considered a religious duty to "go green" through taking steps to safeguard the environment and

${ }^{7}$ The issue of electricity subsidies in the UAE is politically sensitive, as many consider cheap energy a right of citizenship and a way by which wealth is redistributed to the public (The Economist Intelligence Unit, 2010; Krane, 2010). 
preserve the Earth's natural resources (Al-Saleh, 2010). Nonetheless, as pointed out by one of the interviewees, given the diverse fabric of the UAE community, it would be challenging to identify universally effective campaign messages. As affirmed by the interviewee, "it is difficult here because the public are so diverse-you have expats and locals and different issues among different ethnic mixes".

\section{CONCLUDING REMARKS}

Recognising the importance of an informed public in supporting the transition to a CE future, GCC countries have shown a noticeable willingness to generate awareness of the benefits of CE use. This paper provides an examination of recent CEawareness campaigns, including their objectives, the groups they have targeted, the actors involved in these campaigns, and the level of support they have garnered, as well as an analysis of the obstacles, successes and perceptions surrounding these campaigns. Our research indicated that in the UAE, a variety of stakeholders, including governmental, NGOs and private entities, have been exerting significant efforts to raise CE awareness and knowledge levels. However, our findings indicate that the decisionmaking process has primarily been based on a "top-down" approach, where the government has initiated the majority of CE projects. The findings also highlighted the fact that the potential for communityled initiatives and interest groups to bring about grassroots change in the energy mix is currently limited. There is also a perception among policy makers that there isno urgent need to create awareness among the public with regard to CE sources and their potential in the region at the current time. The public's lack of interest in CE sources was also reported to be due greatly to the heavy subsidies supporting domestic conventional energy consumption, such that the cost of using energy is borne by public finances rather than the consumer. Awareness campaigns have also focused more on demand side managementas opposed to creating an awareness of energy sources used.

It was indicated that the reduction of subsidies could allow for a renewed government interest towards initiating public awareness campaigns specifically targeted at raising awareness ofrenewable energy sources. Policy makers would also be advised to initiate greater consultations among stakeholders on their experiencesand interests, and to develop multi-directionalcommunication with the public on issues surrounding CE.The broader public needs to understand the
Clean energy awareness campaigns in the UAE 
IJIKMMENA

2,2 fulleconomic and social costsof the currentenergy system, as well as its unsustainability and the potential of CE to providea growing share of energy supply in the UAE.Future research that stems from this study could take a deeper look at the decision-making process concerning CE in the UAE. This would enable a clearer understanding of the roles and responsibilities of the participating stakeholders in CE developments.

REFERENCES

Abdul Kader, B. (2011), "Survey Shows Increase in Abu Dhabi's Green Awareness" http://gulfnews.com/news/gulf/uae/environment/surveyshows-increase-in-abu-dhabi-s-green-awareness-1.869694

Al-Saleh, Y.M. (2009), "Renewable Energy Scenarios for Major Oilproducing Nations",Futures, Vol. 41 No. 9,pp. 650-662.

Al-Saleh, Y.M. (2010), The Prospects for Sustainable Energy Innovation within Oil-rich GCC Countries. Brighton: WASD, SPRU - University of Sussex.

Al-Saleh, Y. (2011), "Can Environmental Awareness Spur on CleanTech Innovation in the Arab World?" Gulf Times, 28 October 2011.

Al-Saleh, Y.M. and Taleb, H.M. (2010), "The Integration of Sustainability within Value Management Practices: A Study of Experienced Value Managers in the GCC Countries",Project Management Journal, Vol. 41 No. 2,pp. 50-59.

Al-Saleh, Y.M. and Vidican, G. (2011), "Innovation Dynamics of Sustainability Journeys for Hydrocarbon-rich Countries",International Journal of Innovation and Sustainable Development, in Press.

Al-Saleh, Y. (28 October 2011), "Can Environmental Awareness Spur on CleanTech Innovation in the Arab World?" Gulf Times.

Anoop.(8 February 2012), "Abu Dhabi Unveils New Utility Bill for Water and Electricity", H20.http://www.h2ome.net/en/2012/02/abu-dhabiunveils-utility-bill-water-electricity-1

Bauer, M. (1997),Resistance to New Technology: Nuclear Power, Information Technology and Biotechnology, Cambridge University Press,Cambridge.

Boise State University,(2008), "19th Annual Idaho Public Policy Survey",Social Science Research at Boise State University.http://scholarworks.boisestate.edu/ppc_pps/21 
British Wind Energy Association,(2005), "Latest Poll Finds Strong Support for Renewables over Nuclear", British Wind Energy Association. http://www.bwea.com/media/news/populus_nuclear.html

Brohmann, B., Feenstra, Y., Heiskanen, E., Hodson, M., Mourik, R., Prasad, G. and Raven, R. (2007), "Factors Influencing the Societal Acceptance of New, Renewable and Energy Efficiency Technologies: Meta-analysis of Recent European Projects",European Roundtable for Sustainable Consumption and Production, Basel, June 20-22 2007.

Chandrasekar, B. and Kandpal, T.C. (2007), “An Opinion Survey Based Assessment of Renewable Energy Technology Development in India”, Renewable and Sustainable Energy Reviews, Vol. 11 No. 4,pp. 688-701.

Coffman, J. (2002),Public Communication Campaign Evaluation: An Environmental Scan of Challenges, Criticisms, Practice, and Opportunities, Cambridge, Harvard.

Day, B.A. and Monroe, C.M. (1999), Environmental Education and Communication for Sustainable World: Handbook for International Practition ers, Greencom, Washington DC.

Devine-Wright, P. (2005), "Beyond NIMBYism: Towards an Integrated Framework for Understanding Public Perceptions of Wind Energy", Wind Energy, Vol. 8 No. 2,pp. 125-139.

Devine-Wright, P. (2008), "Reconsidering Public Acceptance of Renewable Energy Technologies: A Critical Review",in Delivering a Low Carbon Electricity System: Technologies, Economics and Policy, Grubb, M., Jamasb T., Pollitt, M.G. (Eds.). Cambridge University Press,Cambridge.

Dinh-Zarr, T.B. Sleet, D.A., Shults, R. A. Zaza, S., Elder, R.W., Nichols, J.L., Thompson, R.S.,Sosin, D.M. and the Task Force on Community Preventive Services, (2001),"Reviews of Evidence Regarding Interventions to Increase the Use of Safety Belts",American Journal of Preventive Medicine, Vol. 21No.4S,pp. 48-65.

Dolata, U. (2005), "Reflexive Simulation or Disjointed Incrementalism: Readjustments of National Technology and Innovation Policy",Science, Technology and Innovation StudiesVol. 1 No.1,pp. 59-76.

Doukas, H., Patlitzianas, K.D., Kagiannas, A.G. and Psarras, J. (2006), "Renewable Energy Sources and Rationale Use of Energy Development in the Countries of GCC: Myth or Reality?" Renewable EnergyVol. 31 No. 6,pp. 755-770.
Clean energy awareness campaigns in the UAE 
IJIKMMENA

2,2

EIA (Energy Information Administration), (2010), "Average retail price of electricity to ultimate customers" Available at: http://www.eia.doe. gov/cneaf/electricity/epm/table5_6_a.html

Ekins, P. (2004), "Step Changes for Decarbonising the Energy System: Research Needs for Renewables, Energy Efficiency and Nuclear Power",Energy PolicyVol. 32 No. 17, pp. 1891-1904.

El-Husseini, I., Fayad, W., El-Sayed, T. and Zywietz, D. (2009),A new source of power: the potential for renewable energy in the MENA region. Abu Dhabi: Booz \& Company Inc.

EU-GCC.(2012), "EU-GCC Clean Energy Network”,EU-GCC Website. http://eeas.europa.eu/delegations/gulf_countries/eu_projects_and_programs/energy/index_en.htm

Eurobarometer(2006), “Attitudes towards Energy”,European Commission Website. http://ec.europa.eu/public_opinion/archives/ebs/ ebs_247_en.pdf [accessed 3 April 2012].

Ferroukhi, R., Ghazal Aswad, N., Hawila, D. and Mezher, T. (2012), "Renewable Energy in the GCC: Status, Challenges and Drivers",International Journal of Energy Sector Management, in Press.

Flick, U. (2006),An Introduction to Qualitative Research. London: Sage Publications Ltd.

Frey, J.H. (1993), "Risk Perception Associated with a High Level Nuclear Waste Repository”,Sociological Spectrum, Vol. 13 No. 2,pp. 139-151.

GCC Secretariat General.(2009), "Environmental Cooperation in the GCC", http://www.gccsg.org/eng/index/php?action=sec

Graham, J.B., Stephenson, J.R. and Smith, I.J. (2009), "Public Perceptions of Wind Energy Developments: Case Studies from New Zealand",Energy Policy, Vol. 37 No. 9,pp. 3348-3357.

Hurworth, R. (1996), "Qualitative Methodology: Common Questions about Running Focus Groups during Evaluations”,Evaluation News and Comments, Vol. 5 No. 1, pp. 40-52.

Jacobsson, S. and Lauber, V. (2005), "Germany: From a Modest Feed-in Law to a Framework for Transition", in Switching to Renewable Power: a Framework for the 21st Century, Lauber, V. (Ed.). Earthscan Publications Ltd,London. 
Jackson, T. (2005), "Motivating sustainable consumption: a review of evidence on consumer behaviour and behavioural change", International Sustainability Workshop, Washington DC, 18-20May 2005.

Krane, J. (2010),The Basis of Abu Dhabi's Quest for Renewable Energy and Policies Required to Meet its Goals, Dubai School of Government, Working Paper 10-08.

Kyung-Hee, K. (2007), "Overview on Public Benefit Campaigns to Promote Energy Conservation and Energy Efficiency", The United Nations Forum on Energy Efficiency and Energy Security: Taking Collaborative Action on Mitigation Climate Change, Seoul, 17-18 December 2007.

Lauber, V. and Mez, L. (2004), "Three Decades of Renewable Electricity Policies in Germany",Energy and EnvironmentVol. 15 No. 4, pp. 599-623.

Levitt, T. (2009),“Carbon Emissions: The World in 2010”,The Ecologist. http://www.theecologist.org/News/news_analysis/383922/carbon_ emissions_the_world_in_2010.html

Luomi, M. (2009), “Abu Dhabi's Alternative-energy Initiatives: Seizing Climate-change Opportunities",Middle East PolicyVol. 16 No. 4, pp. 102-117.

Manjunath, D.L. (2007),Environmental Studies. New Delhi: Dorling Kindersley.

Mezher, T., Dawelbait, G. and Abbas, Z. (2011),"Renewable energy policy options for Abu Dhabi: drivers and barriers", Working paper, Energy Policy, Engineering Systems and Management Department, Masdar Institute.

Okaka, W. (2002), "An Environmental Education Program: Uganda Polytechnic kyambogo",Applied Environmental Educational and Communication, Vol. 1 No. 1,pp. 45-52.

Owens, S. and Driffil, L. (2006), "How to Change Attitudes and Behaviours in the Context of Energy",Energy Policy, Vol. 36 No. 12,pp. 4412-4418.

Qader, M.R. (2009),"Electricity consumption and GHG emissions in GCC countries", Energies, Vol. 2 No. 4, pp. 1201-1213.

Raouf, M.A. (2008), "Climate Change Threats, Opportunities, and the GCC Countries",The Middle East Institute Policy Brief 2. http:// www.mei.edu/sites/default/files/publications/CLIMATE-CHANGETHREATS-OPPORTUNITIES-GCC-COUNTRIES.pdf

Clean energy awareness campaigns in the UAE

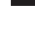


IJIKMMENA

2,2

Reiche, D. (2009), "Renewable Energy Policies in the Gulf Countries: A Case Study of the Carbon-Neutral 'Masdar City' in Abu Dhabi",Energy Policy, Vol. 38 No. 1,pp. 378-382.

Reiche, D. (2010),"Energy Policies of Gulf Cooperation Council Countries - Possibilities and Limitations of Ecological Modernization in Rentier States",Energy Policy, Vol. 38 No. 5,pp. 2395-2403.

Robitaille, L. and Etcheverry,J. (2005),"Training, Education, and Public Awareness: Key Components for Developing a Strong and Vibrant Canadian Solar Industry",SESCI 2005 Conference British Columbia Institute of Technology Burnaby, British Columbia, 20-24 August 2005.

Rogers, E.M. (1995),Diffusion of Innovations. The Free Press,New York.

Saunders, M., Lewis, P. and Thornhill, A. (2007),Research Methods for Business Students. Pearson Education Ltd,London.

Savvanidou, E., Zervas, E. and Tsagarakis, K.P. (2010), "Public Acceptance of Biofuels", Energy Policy, Vol. 38 No. 7,pp. 3482-3488.

Sawin, J.L. (2004),Mainstreaming Renewable Energy in the 21st Century, Worldwatch Institute,Danvers.

Taleb, H.M. and Pitts, A.C. (2009), "The Potential to Exploit Use of Building-integrated Photovoltaics in Countries of the Gulf Cooperation Council",Renewable Energy, Vol. 34 No. 4,pp. 1092-1099.

The Cooperation Council for the Arab States of the Gulf.(2009), "The Charter" http://www.gccsg.org/eng/index.php

Theeyattuparampil, V., Vidican, G. and Al-Saleh, Y.M. (2012), "Challenges and Opportunities for the Emerging CCUS Innovation System in the UAE",International Journal of Innovation and Learning, in Press.

Toke, D. (2002), "Wind Power in UK and Denmark: Can Rational Choice Theory Help Explain Different Outcomes?" Environmental Politics, Vol. 11 No. 4,pp. 83-100.

Toumi, H. (28 September 2011), "Arab Spring will not extend to GCC: Kuwaiti MP",Gulf News.

Upham P. and Shackley, S. (2006), "Stakeholder Opinion of a Proposed 21.5MWe Biomass Gasifier in Winkleigh, Devon: Implications for Bioenergy Planning and Policy",Journal of Environmental Policy and Planning, Vol. 8 No. 1,pp. 45-66. 
Upreti, B.R. (2004), "Conflict over Biomass Energy Development in the United Kingdom: Some Observations and Lessons from England and Wales”,Energy Policy, Vol. 32 No. 6,pp. 785-800.

Vidican, G., McElvaney, L., Samulewicz, D. and Al-Saleh, Y.M. (2012), "An Empirical Examination of the Development of a Solar Innovation System in the UAE",Energy for Sustainable Development, in Press.

Walter, G. and Gutscher, H. (2011),Public Acceptance of Wind Energy and Bioenergy Projects in the Framework of a Distributive and Procedural Justice Theories. Zurich: Zurich University.

Warren, C.R., Lumsden, C., O’Dowd, S. and Birnie, R.V. (2005),“Green on Green: Public Perceptions of Wind Power in Scotland and Ireland",Journal of Environmental Planning and Management, Vol. 48 No. 6, pp. 853-875.

World Public Opinion.(2006), "19 Nation Poll on Energy: Questionnaire and Methodology" World Public Opinion Website. http://www. worldpublicopinion.org/pipa/pdf/jul06/Energy_Jul06_quaire.pdf [accessed 6 April 2012].

Zoellner, J., Schweizer-Ries, P. and Wemheuer, C. (2008), "Public Acceptance of Renewable Energies: Results from Case Studies in Germany",Energy Policy,Vol. 36 No. 11,pp. 4136-4141.

\section{APPENDIX A: INTERVIEW PROTOCOL}

\section{General}

- What is your personal and educational background?

- Can you provide us with an overview of your career path?

- What is the mandate of the organisation you work in and what are your activities/responsibilities?

The What, Where and How of CE Awareness Campaigns in the UAE

- Have there been efforts to raise public awareness on CE?

- What have been the specific objectives of such initiatives?

- Which institutions have led/been behind such initiatives? Has it always been a federal institution? Have there been initiatives taken at the local level or by civil society entities?

Clean energy awareness campaigns in the UAE $+$ 
IJIKMMENA

2,2

- Which other stakeholders have been involved in/contributed to such initiatives (energy agencies, local initiatives, NGOs, public utility companies, service providers, etc.)?

- Who have/should CE awareness campaigns target (energy consumers, children [future energy consumers], educators, manufacturers and other businesses, government agencies)?

- What have been the preferred communicationtools when delivering CE awareness campaigns to audiences (electronic media, popular media, print media, multi-media formats, etc.)?

- How willing has the public been to participate in CE awareness campaigns? Have they been mostly receptors of such information or have they also had a more active role?

- What messages are most effective to use in a successful public awareness campaign in UAE?

\section{Barriers and drivers for CE Public Awareness Campaigns in the UAE}

- What are the maindrivers to the development of successful CE awareness campaigns?

- It has been said that some of the barriers faced by environmental NGO's working in the GCC region include problems such as lack of funds and volunteers. What would you say are the mainbarriers to the development of successful CE awareness campaigns?

- Is there sufficient awareness among the campaign practitioners, evaluators and their sponsors about the right methods for effective CE awareness campaigns and the need for such initiatives? What methods are most effective in UAE to educate public (newspaper, internet, TV, brochures, leaflets, posters/public ads...)?

- Are there sufficient publicbudget allocations for RE awareness campaigns?

- How would you assess current national RE awareness campaign strategies? What level of support/impact have these initiatives garnered?

- Until recently, public participation has been restricted to supporting government policies rather than influencing their direction, not to mention questioning the utility of these policies. Has this worked to the benefit or disadvantage of the UAE's green agenda? 


\section{ABOUT THE AUTHORS}

Noor Ghazal Aswad is a Junior Programme Officer at the Policy Advice and Capacity Building Directorate at the International Renewable Energy Agency (IRENA). She has an MSc in Engineering Systems Management from Masdar Institute of Science and Technology (in collaboration with Massachusetts Institute of Science and Technology) and a BSc in Architectural Engineering from United Arab Emirates University. Her research interests lie in the area of renewable energy policy and sustainable development.

Dr.Yasser Al-Saleh comes from an engineering background and has previously worked in the oil industry. He was awarded a $\mathrm{PhD}$ from the Manchester Institute of Innovation Research (at The University of Manchester) for his novel examination of the emergence of clean-tech industries using an innovation system perspective. His current research work spans several major areas including innovation policy, sustainability transitions, dynamics of technological change, foresight studies and renewable energy policy. Over the past few years, he has published over twenty peer-reviewed academic papers, and in 2010, he published his first book entitled "The Prospects for Sustainable Innovation within Oil-rich Gulf Cooperation Council". Dr Al-Saleh frequently reviews papers for scholarly journals and he currently sits on the editorial board of several academic journals.

Dr.HananTaleb works at the British University in Dubai as an Atkins Assistant Professor in the MSc Sustainable Design of the Built Environment Programme. She was awarded her PhD from the School of Architecture at the University of Sheffield for her research on sustainable residential buildings in Saudi Arabia. Besides undertaking extensive postgraduate studies in the field of sustainable architecture in the UK, she holds postgraduate certificates in educational leadership and curriculum development from the University of Leicester. Over the past few years, Dr Taleb has both presented papers at international conferences and published a number of peer-reviewed journals on a wide range of sustainability-orientated subjects. Her current research interests include sustainability assessment tools, passive solar design, smart infrastructure and energy-efficient buildings.
Clean energy awareness campaigns in the UAE 